\title{
THE INFLUENCE OF EXTRUSION PROCESS ON THE MICROSTRUCTURE AND MECHANICAL PROPERTIES OF MAGNESIUM ALLOYS
}

\begin{abstract}
The article presents the results of plastic shaping tests of AZ61 and WE43 alloys. There were both classic extrusion tests as well as extrusion tests of KOBO method. An assessment was made of the influence of extrusion process parameters on the mechanical properties and the structure of the alloys. On the basis of achieved results of mechanical properties for alloys AZ31 and WE43 the susceptibility of those alloys to plastic shaping was determined. Quantitative tests of structure assessment in case of alloys AZ61 and WE43 after extrusion with the use of KOBO method were conducted with the use of METILO program. It has been shown that extrusion AZ61,WE43 alloys method KOBO leads to considerable fragmentation of grains.
\end{abstract}

Keywords: magnesium alloys, microstructure, mechanical properties, the process of extrusion method KOBO

\section{Introduction}

Nowadays, a growing demand is observed in aviation industry for spare parts made of light alloys which are sufficiently stiff and resistant. Limited application of magnesium alloys till present has resulted mainly from their susceptibility to corrosion (main disadvantage), flammability, low resistance, high cost of processing by means of plastic working and bad mechanical workability [1-2]. Elaboration of new coatings which could protect alloys against corrosion as well as new alloys, new technologies of achievement of semi-products with the use of casting and improvement of plastic shaping technologies all caused a comeback of interest in those materials. The most famous alloys are from group $\mathrm{Mg}-\mathrm{Al}-\mathrm{Zn}$. In this group there are four basic kinds: AZ21, AZ31, AZ61 and AZ80. Alloys AZ61 and AZ80 include the biggest amount of alloy elements and show the most beneficial mechanical properties. Alloy AZ61 is plastically processed with the use of extrusion and forging. It has more beneficial properties than alloy AZ31 [3-4]. The second group of alloys is $\mathrm{Mg}-\mathrm{Y}-\mathrm{Re}-\mathrm{Zr}$, where WE43 can be found and which is an alloy which can be plastically workable alloy mostly with the use of extrusion [5-6]. Alloy WE43 can be applied in aviation industry for construction elements due to invariance of resistance properties up to temperature of $250^{\circ} \mathrm{C}$. It is characterised with big resistance in elevated temperature and resistance to creep in comparison with other magnesium alloys [7-8]. The paper presents shaping process conducted by means of extrusion with KOBO method which is among the unconventional methods of plastic shaping of metals and alloys with the use of big deformations-SPD (Severe Plastic Deformations). It is based on application of additional reverse die torsion with given angle with determined frequency. The tests conducted so far have shown that there is a possibility to shape magnesium alloy with very big deformations without the need of prior heating of the charge. What is more, the achieved products are characterised with high resistance properties and good plastic properties [9-11].

\section{Experimental procedure}

Materials for extrusion process were ingots from magnesium alloys: AZ61 and WE43 with measurements $\phi 40 \times 65 \mathrm{~mm}$. Chemical composition of the alloys presented in Table 1.

TABLE 1

Chemical compositions of: a) AZ61, b) WE43 (at.\%)

a)

\begin{tabular}{|c|c|c|c|c|c|c|}
\hline \hline Alloy & Al & Zn & Mn & Cu & Fe & Ni \\
\hline AZ61 & 6,2 & 0,61 & 0,22 & 0,01 & 0,002 & 0,0009 \\
\hline
\end{tabular}

b)

\begin{tabular}{|c|c|c|c|c|c|c|c|c|c|}
\hline \hline Alloy & Y & HRE+Nd & Nd & Zr & Zn & Si & Cu & Ag & Fe \\
\hline WE43 & 4 & 3 & 2,2 & 0,54 & 0,03 & 0,01 & 0,01 & 0,01 & 0,002 \\
\hline
\end{tabular}

Ingots after casting underwent homogenisation in time of $2 \mathrm{~h}$ in temperature of $400^{\circ} \mathrm{C}$. The process of plastic deformation for both tested alloys was conducted with the use of classic ex-

\footnotetext{
SILESIAN UNIVERSITY OF TECHNOLOGY, FACULTY OF MATERIAL SCIENCE AND METALLURGY, 8 KRASIŃSKIEGO STR.,40-019 KATOWICE, POLAND

\# Corresponding author: iwona.bednarczyk@polsl.pl,
} 
trusion on hydraulic press. Ingots from alloys AZ61 and WE43 sized $\phi 40 \times 65 \mathrm{~mm}$ were deformed to the the form of rods with diameter of $\phi 8 \mathrm{~mm}$ with the use of hydraulic press. Due to technological difficulties the rods with a diameter of $\phi 6 \mathrm{~mm}$ could not be achieved. The second method of deformation was the extrusion KOBO method. Alloys AZ61 and WE43 were directly extruded in room temperature without the prior heat with the speed of punch traverse of $0.2 \mathrm{~mm} / \mathrm{s}$ and die torsion angle of $\pm 8^{\circ}$ with frequency of $5 \mathrm{~Hz}$ (Fig. 1). The material was intensely cooled with water on the press throat. Rods with diameter of $\phi 6 \mathrm{~mm}$ were achieved.

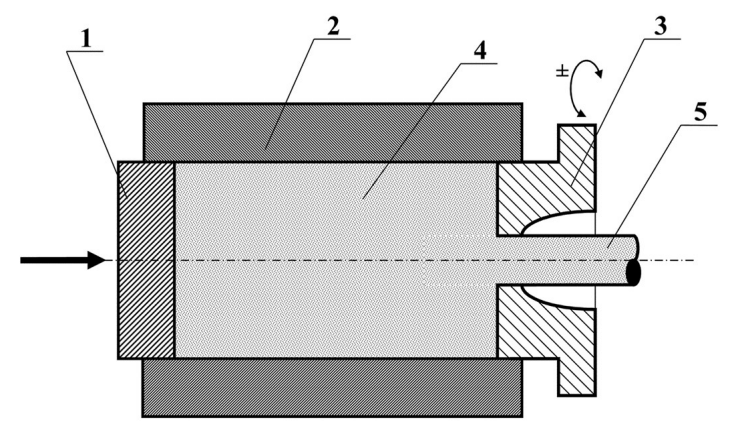

Fig. 1. Diagram of direct extrusion: 1 - punch, 2 - container, 3 - cyclic rotated die with grooves on face area surface, 4 - extruded material, 5 - charge/product [2]

The analysis of microstructure of magnesium alloys in initial condition and after extrusion was conducted with the use of light and electron microscopy techniques. Tests of mechanical properties were determined on testing machine ZWIK/Z100 in room temperature. There were micro-hardness measurements made with the use of Vickers method in initial state and after extrusion in KOBO method. There were also fractographic tests conducted which were aimed at determination of fracture character with the use of scanning microscope Hitachi S-4200. Quantitative structure assessment tests were conducted with the use of METILO program [5]. Stereological parameters were marked such as: mean grain size and mean grain diameter were marked on the basis of images registered on light microscope.

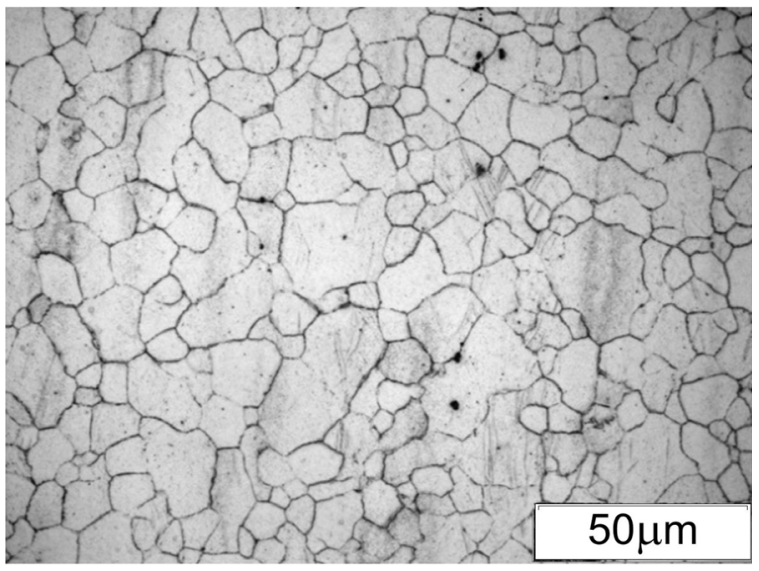

a)

\section{Results and discussion}

Chosen microstructures of tested alloys after casting and homogenization were shown in Fig. 2. Alloys AZ61 and WE43 are characterised with coarse-grained structure with varied grain sizes. Structure of alloy WE43 has heterogeneous grains with different sizes and the mean area of a grain plane section equalled $\bar{A}=99.7 \mu \mathrm{m}^{2}$ and mean grain diameter $d=10.7 \mu \mathrm{m}$. In case of alloy AZ61 there was also a heterogeneous structure observed with varied grain sizes. Mean grain diameter equalled $d=9.48 \mu \mathrm{m}$ and mean area of a grain plane section equalled $\bar{A}=70.2 \mu \mathrm{m}^{2}$.

Figure 3 shows chosen structure images after classic extrusion and extrusion in the use of KOBO method. In the structure of alloys AZ61 and WE43 after classic extrusion there was a coarse-grain structure found. Application of classic extrusion method influenced the achievement of materials which had fine and recrystallised grains (Fig. 3a). The best results after application of classic method of extrusion were achieved for alloy WE43 (Fig. 3a). Results of quantitative analysis of alloys AZ61 and WE43 structures are presented in Fig. 4 and Fig. 5. Application of extrusion KOBO method for both alloys allowed for the achievement of fine-grained structures. The biggest grain refining was achieved for alloy WE43. After extrusion with the use of KOBO method the mean diameter of grain equalled $0.9 \mu \mathrm{m}$ (Fig. 5b) and decreased in comparison with initial state (Fig. 3b). Figure 5 presents the results of mean grain surface area and shape factor for alloy WE43. It can be read from grain-size distribution (Fig. 5a) that such value after extrusion process with $\mathrm{KOBO}$ method had 100 times decreased in comparison with initial state (after casting $\bar{A}=99.70 \mu \mathrm{m}^{2}$, after deformation $\bar{A}=0.51 \mu \mathrm{m}^{2}$ ). Grain surface area is between 0.045 and $2.894 \mu \mathrm{m}^{2}$ and most grains matches the lower sizes in this range. Structure of alloy WE43 after extrusion with KOBO method is characterised with a structure with more equiaxial grains than the structure after casting process which is visible in the classic shape factor (after deformation the shape factor equalled 0.73, after casting process-0.58). Also in case of alloy AZ61 which underwent the process of KOBO method the conducted quantitative analysis confirmed that the structure underwent refinement and the results

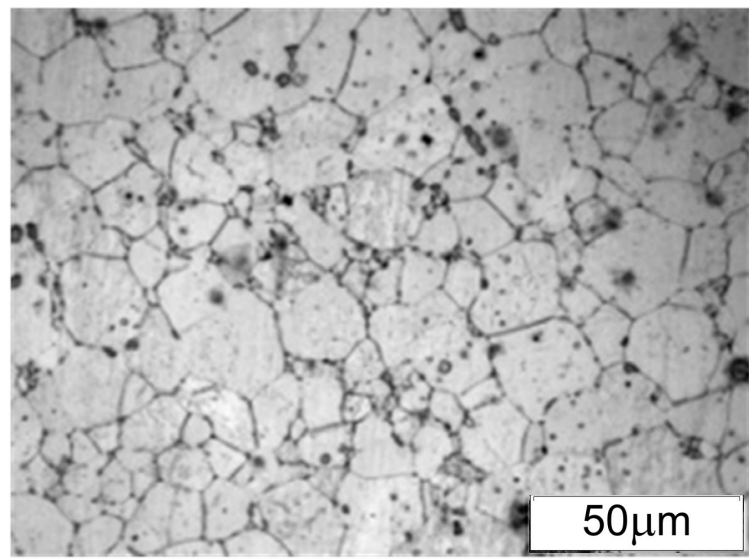

b)

Fig. 2. Microstructure of the casting process and heat treatment: a) AZ61, b) WE43 

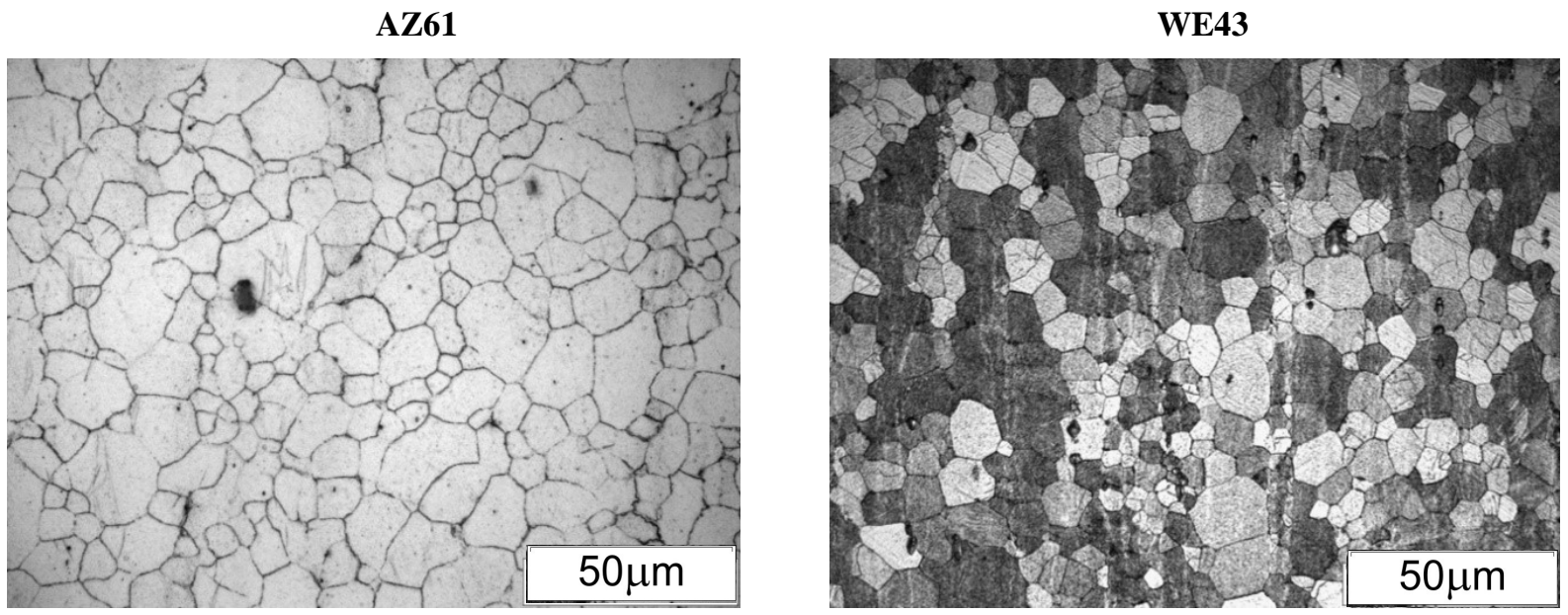

a)
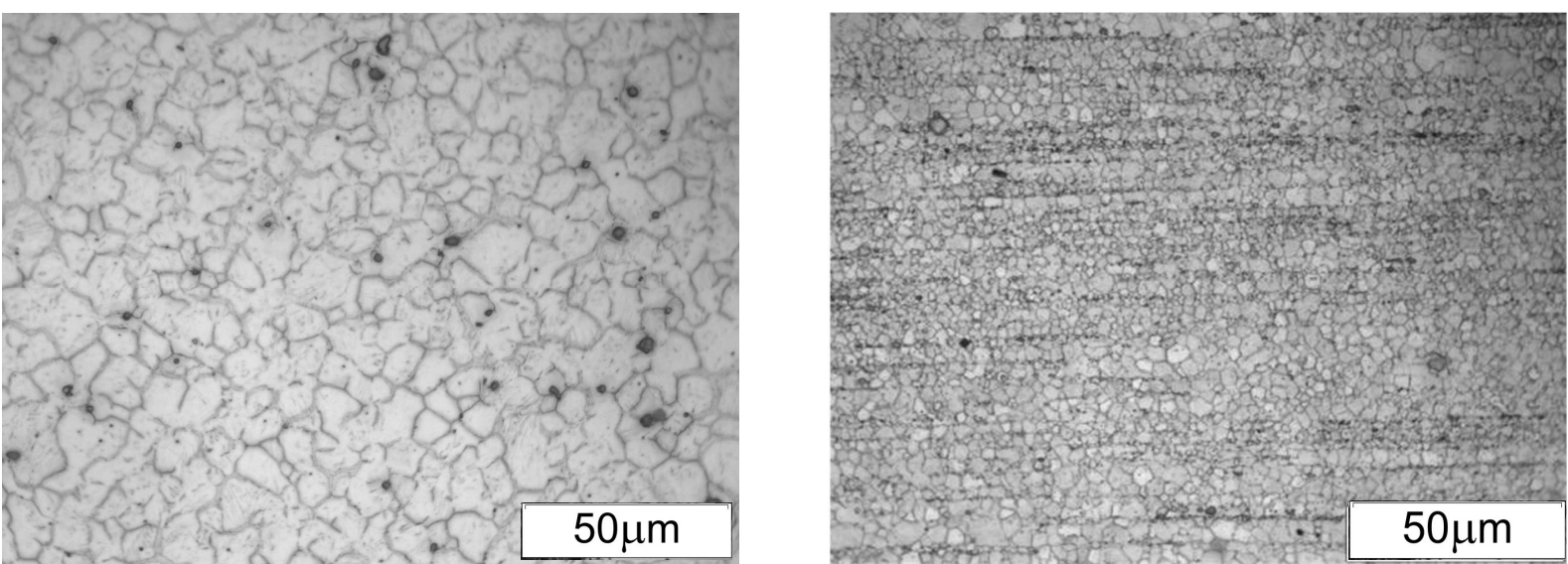

b)

Fig. 3. Microstructure of AZ61, WE43 alloys after the process of: a) classic extrusion, b) extrusion KOBO method

equal respectively: mean grain diameter $d=6.53 \mu \mathrm{m}$ and decreased in comparison with initial state $(d=9.48 \mu \mathrm{m})$ whereas the mean surface area of grain plane section equalled $\bar{A}=30.46 \mu \mathrm{m}^{2}$. Figure 6 presents results which are connected with the mean surface area of grain and shape factor for alloy AZ61. Surface area distribution of grain plane section (Fig. 6a) shows that the parameter after extrusion with KOBO method was more than halved in comparison with the initial state (after casting process $\bar{A}=70.2 \mu \mathrm{m}^{2}$, after deformation process $\bar{A}=30.46 \mu \mathrm{m}^{2}$ ). After extrusion with $\mathrm{KOBO}$ method the analysis of microstructure was conducted with the use of techniques of scanning-transmission microscopy (STEM). It was found in case of both alloys that the recrystallised structure is present. There were also recrystallised grains found which were dislocation-free (Fig. 7).

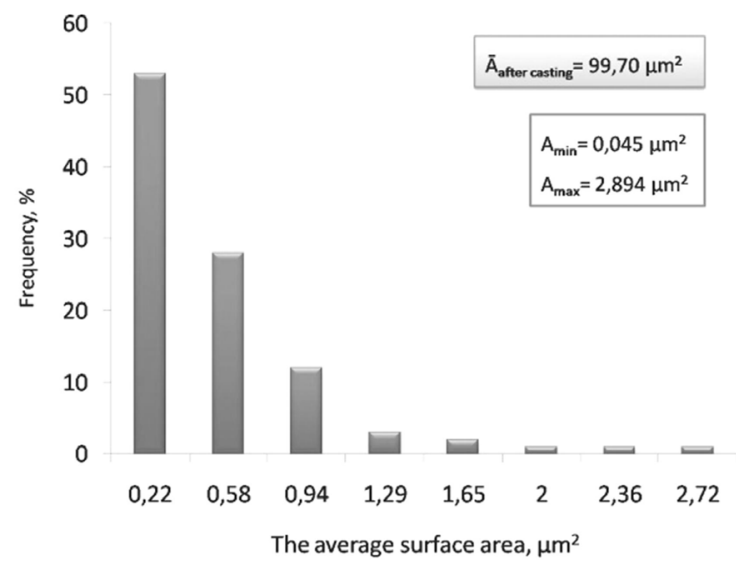

a)

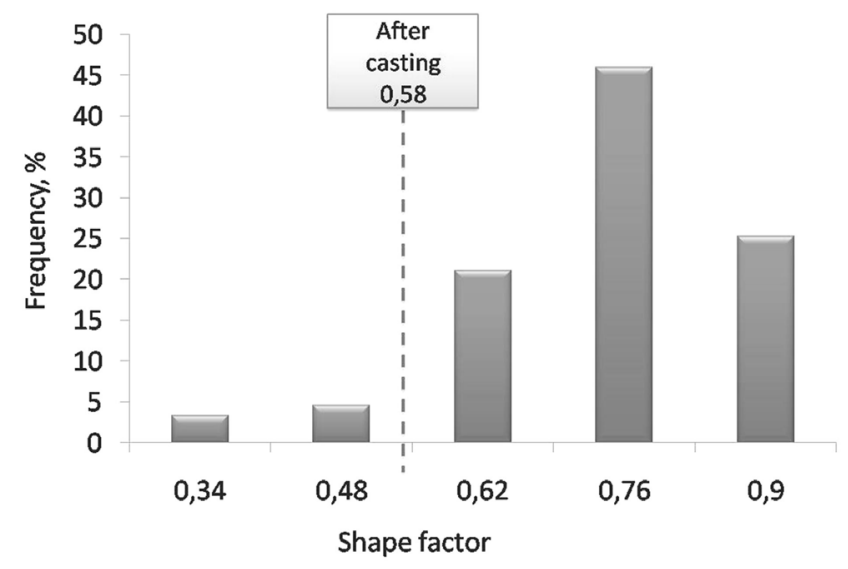

b)

Fig. 4. The average surface area, b) the shape index grain size of the alloy WE43 after the extrusion KOBO method 


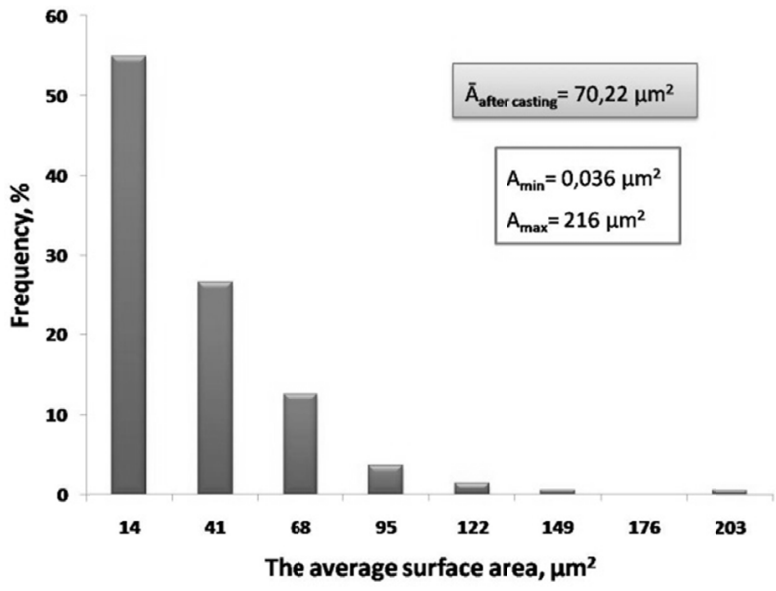

a)

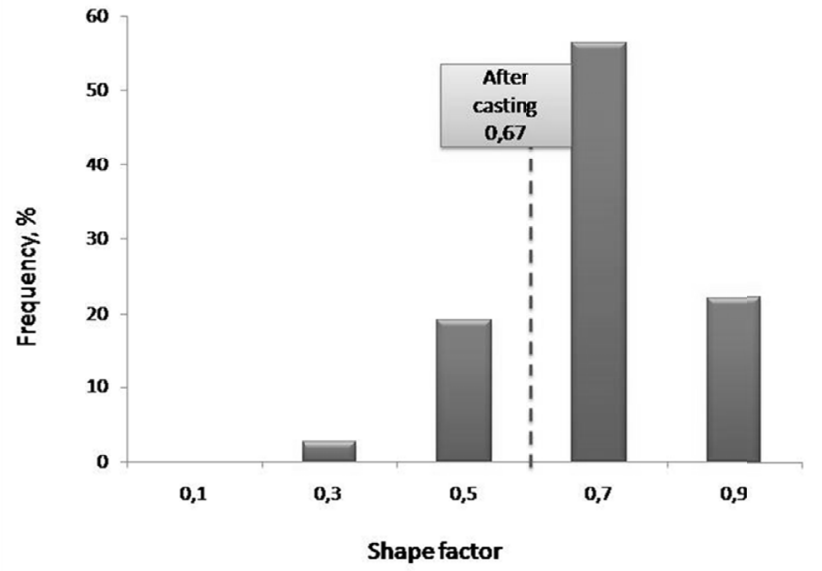

b)

Fig. 5. The average surface area, b) the shape index grain size of the alloy AZ61 after the extrusion KOBO method

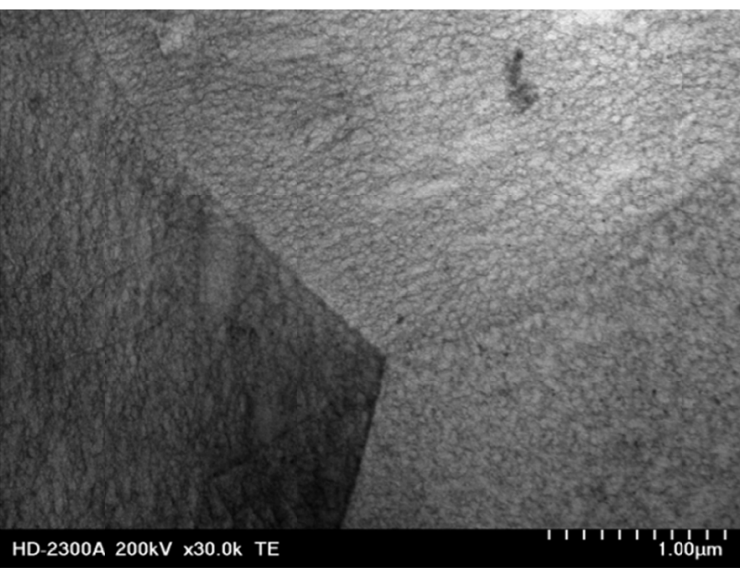

a)

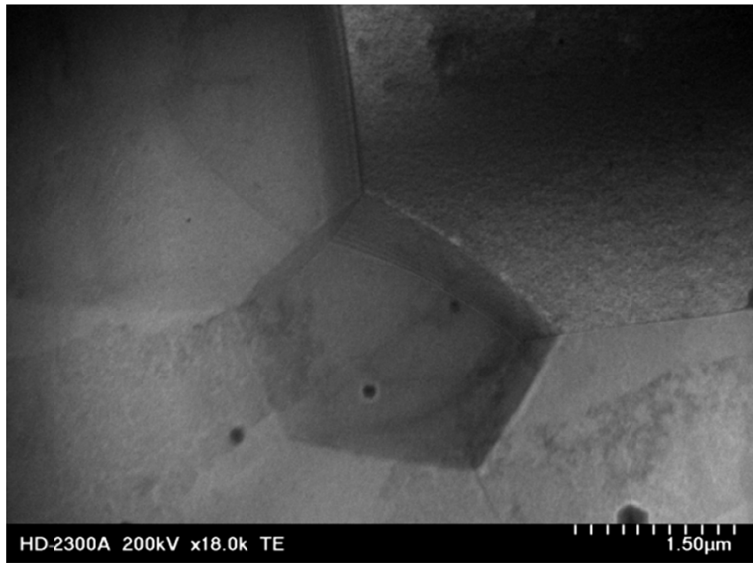

b)

Fig. 6. Substructure of alloys after extrusion KOBO method: a) AZ61, b) WE43

The examples of tension curve of stress-elongation for both alloys in room temperature are presented in Fig. 7. Results of mechanical properties for alloys AZ61 and WE43 are presented in table 2 . It was stated for both tested alloys that there an increase, both elongation and reduction in area after KOBO method. There was almost doubled increase of elongation values

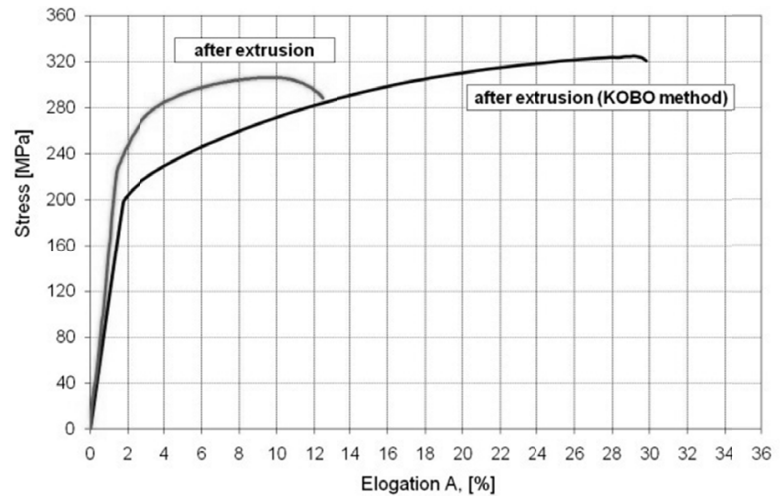

a) achieved (AZ61-27\%, WE43-55\%) in comparison with classic extrusion method (AZ61-12\%, WE43-20\%). Whereas the resistance properties after tension in room temperature for both alloys are similar on both extrusion processes used (Fig. 7). After conducted strength tests some fractographic tests were made in order to determine the character of the fracture which occurred.

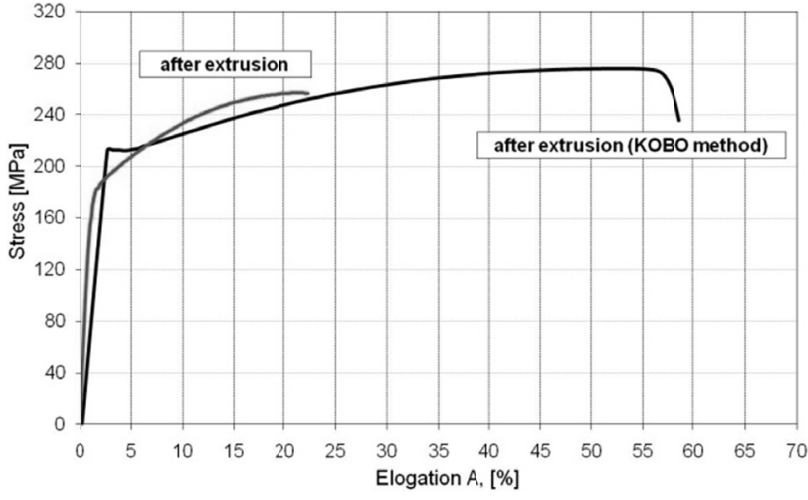

b)

Fig. 7. Strain curvefor the investigated at room temperature: a) AZ61, b) WE43 
Figure 8 presents the chosen micro-photos of fractures of AZ61 and WE43 (Figs. 8,9). In room temperature, after classic extrusion there was a mixed ductile fracture achieved with areas of brittle cracking for both alloys (Figs. 8,9). Samples after extrusion with $\mathrm{KOBO}$ method are characterised with bigger presence of ductile fracture after tension. The depth of the observed craters proves the bigger ductility (Figs. 8b,9b). There are intermetallic phase precipitations visible in the area where the process of cracking is initiated.

TABLE 2

Results of tensile testing at the tested alloys at room temperature

\begin{tabular}{|l|c|c|c|c|}
\hline \hline & YS [MPa] & UTS [MPa] & A [\%] & Z [\%] \\
\hline AZ61-after extrusion & 230 & 305 & 12 & 23 \\
\hline $\begin{array}{l}\text { AZ61-after extrusion } \\
\text { KOBO method }\end{array}$ & 210 & 324 & 27 & 39 \\
\hline WE43-after extrusion & 185 & 257 & 20 & 45 \\
\hline $\begin{array}{l}\text { WE43-after extrusion } \\
\text { KOBO method }\end{array}$ & 215 & 275 & 55 & 70 \\
\hline
\end{tabular}

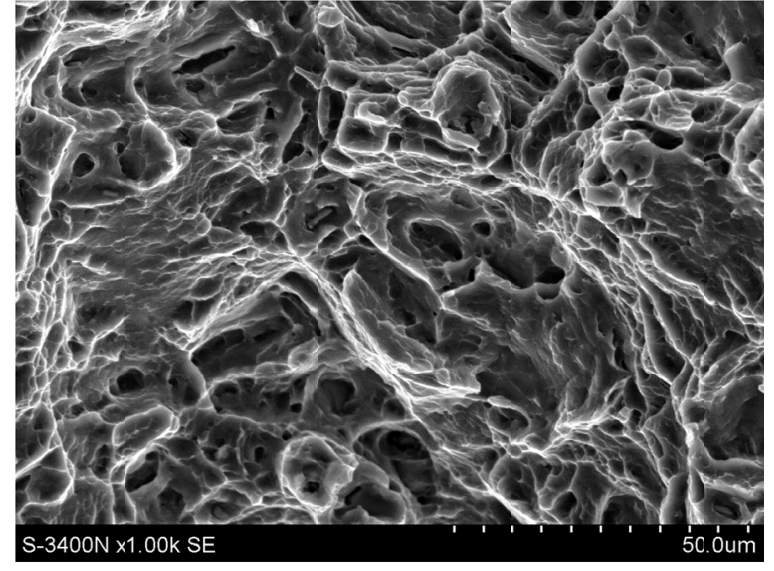

a)
Figure 10 presents the results of measurements of microhardness in initial state and after the process of extrusion in KOBO method. Alloy AZ61 is characterised with similar values of micro-hardness in initial state and after the process of extrusion with the use of KOBO method. Alloy WE43, however, is characterised with higher micro-hardness after extrusion process with $\mathrm{KOBO}$ method in comparison with initial state. The differences may result from the significant grain refining after extrusion with KOBO method (Fig. 10).

\section{Conclusions}

The paper presents conducted tests aimed at determination of the influence of an extrusion on the microstructure and mechanical properties of AZ61, WE43 alloys. Tested alloys in initial state were characterised with comparable microstructure which can be found in the results of grain size measurements. Achieved results after deformation in complex state of deformation with

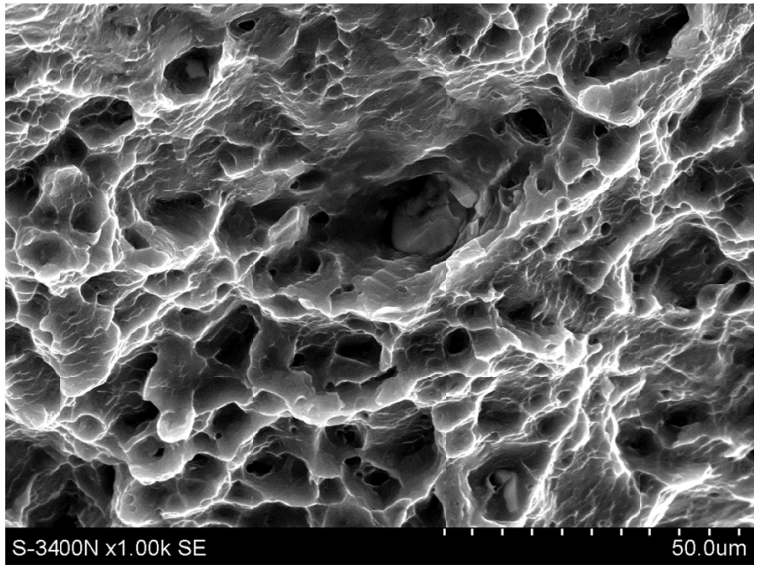

b)

Fig. 8. Results of fractographic tests of sample fractures in alloy AZ61 after static tension test in room temperature after: a) classic extrusion, b) extrusion $\mathrm{KOBO}$ method

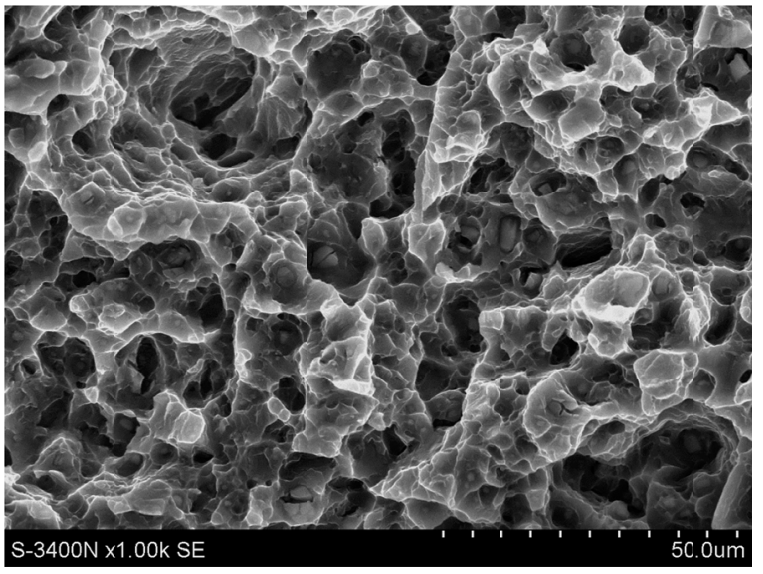

a)

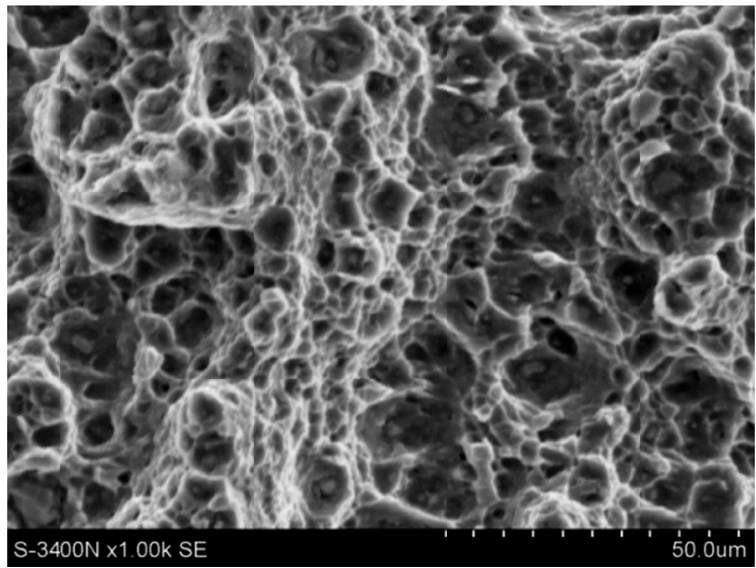

b)

Fig. 9. Results of fractographic tests of sample fractures in alloy WE43 after static tension test in room temperature after: a) classic extrusion, b) extrusion $\mathrm{KOBO}$ method 


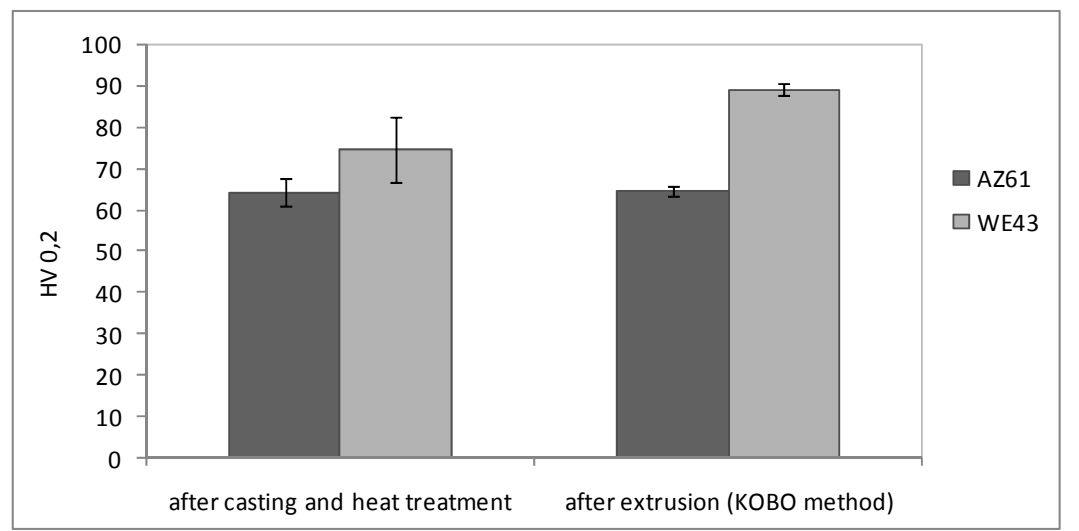

Fig. 10. Results of micro-hardness measurements for alloys AZ61, WE43 in initial state and after extrusion KOBO method

KOBO method were compared with the results achieved in classic extrusion process. It should be pointed out that due to the low deformability of the magnesium alloys the charge for classic extrusion was heated to $400^{\circ} \mathrm{C}$ and in case of KOBO method this operation could be omitted as proved in prior research works [3]. In both cases there were rods achieved with no surface defects and micro-crackings. A significant refinement of grains was found in both tested alloys, much bigger in case after deformation in complex state with KOBO method. The best results were achieved for alloy WE43. It can be caused by the presence of intermetallic phases which have in their composition the rare earth elements and zirconium which block the grain growth during the recrystallisation process which was confirmed in the tests of substructure. The presence of recrystallised grains was found and the migration of the wide-angle boundary which confirm the recrystallisation process. Conducted tests of mechanical properties confirmed the achievement of good mechanical properties and resistance properties for both tested alloys.

\section{REFERENCES}

[1] E. Hadasik, D. Kuc, G. Niewielski, R. Śliwa, Hutnik-Wiadomości Hutnicze (8), 580-584 (2010).
[2] W. Bochniak, A. Korbel, P. Ostachowski, S. Źiółkowicz, J. Borowski, Plastic treatment of metals, Metal Forming 24 (2), 83-97, (2013).

[3] E. Hadasik, D. Kuc, Plastic treatment of metals, Metal Forming 24 (2), 131-147 (2013).

[4] A. Mrugała, I. Bednarczyk, Hutnik- Wiadomości- Hutnicze (8), 533-536 (2015).

[5] J. Szala, Application of computer picture analysis methods to quantitative assessment of structure in materials, Scientific Journals of Silesian University of Technology, Series Metallurgy, Gliwice, (2008).

[6] D. Kuc, E. Hadasik, I. Schindler, A. Mrugała, Metal 2015, 24th International Conference on Metallurgy and Materials, 351-357, Brno 2015, Czech Republic.

[7] J. Bohlen, D. Letzig, K.U. Ulrich, Materials Science Forum (1-10), 546-549 (2007).

[8] A. Mrugała, I. Bednarczyk, P. Ostachowski, M. Lagoda, Rudy Metale R61 (3), 136-139 (2016).

[9] A. Korbel, W. Bochniak, J. Borowski, L. Błaż, P. Ostachowski, M. Łagoda, Journal of Materials Processing Technology 216, 160-168, (2015).

[10] A. Korbel, W. Bochniak, Philosophical Magazine 93 (15), 18831913 (2013).

[11] A. Korbel, W. Bochniak, P. Ostachowski, A. Paliborek, International Journal of Materials Research 102 (10), 974-79 (2013). 